\title{
Revisión de Temas 2. Toxoplasmosis y Gestación
}

\author{
El $1 \%$ de las gestaciones "normales" culmina trágicamente: \\ Toxoplasmosis congénita. \\ Dr. Jaime Wiesner, M.D.
}

\begin{abstract}
Hasta hace escasos cuatro años el diagnóstico de toxoplasmosis congénita en una institución para niños únicamente - Instituto Roosevelt de Bogotá- era inexistente. La evidencia de diez niños con este diagnóstico en un solo nosocomio, nos hace llamar la atención nacional, máxime si se tiene en cuenta que el último "Estudio Nacional de Salud" llegó a demostrar que el $1 \%$ de las gestantes, aproximadamente, tenía alto riesgo de tener un hijo con toxoplasmosis congénita, en nuestro país.
\end{abstract}

Esta infección grave por la severidad e irreversibilidad de las lesiones que causa en los niños, totalmente prevenibles; asi, una profilaxis adecuada es absolutamente indispensable para acabar con esta causa de invalidez infantil total e irreparable.

En 1908, Charles Nicolle y Louis Manceax comunicaron a la Academia de Ciencias de París el aislamiento de un nuevo parásito, al que por su forma arqueada llamaron "Toxoplasma" (toxos-arco), gondii, por haberle encontrado en unos pequeños roedores de este nombre. En 1923 el of talmólogo Janku encontró quistes parecidos al de toxoplasma en la retina de un niño con hidrocefalia, microftalmos y coloboma. Sin dar mayor importancia a este hecho, la enfermedad permaneció inadvertida hasta 1937, en que Wolf, Cowen y Paige, describieron por primera vez un caso mortal producido por toxoplasma; se trataba de un niño con una meningoencefalomielitis, consiguiendo la primera transmisión experimental a partir del líquido cefalorraquídeo.

En 1952, Siim describe el primer caso de toxoplasmosis ganglionar, proceso que hoy se conoce con el nombre de linfadenitis toxoplásmica o enfermedad de Siim.

La Toxoplasmosis es una enfermedad infecciosa causada por Toxoplasma gondii, clasificado como un protozoario intracelular obligado; es un coccidiode del gato, su huésped definitivo. Todas las cepas son antigénicamente similares, sólo existe una especie. Los trofozoitos miden de dos a cinco um. y pueden presentar formas redondeadas, ovales o de media luna; se pueden encontrar libremente en los tejidos, pero generalmente se mueven en el huésped dentro de las células; se dividen por endodiogenia y se tiñen mejor con el colorante de Wrignt o Giemsa; es un parásito único en cuanto a que puede invadir cualquier célula nucleada de animales de sangre caliente; se puede mantener en ratones, cultivo de tejidos o huevos de embrión, pero requiere de células vivas, en cuyo citoplasma se múltiplica. En condiciones especiales es factible almacenarlo en estado de congelación, pero se destruye por congelación ordinaria. 


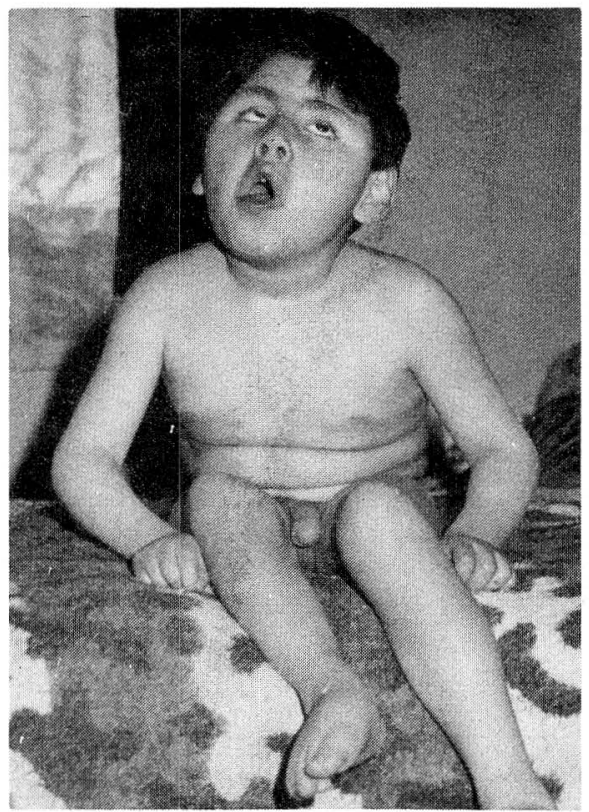

Permanece vivo en los tejidos envueltos en una capa quística, especialmente en músculo y sistema nervioso central. Estos quistes no se calcifican, tienen una membrana bien delimitada, flexible, que alcanza a tener 100 um. de tamaño y que contiene millares de zoítos. Después de ingerir los quistes en la carne o los quistes en las heces de gato, los félidos susceptibles adquieren la infección y desarrollan inmunidad al producir anticuerpos. Estos mismos materiales son también infectantes para otros animales, pero sólo en los gatos y otros félidos se llevan a cabo los ciclos esquizogénicos en la luz intestinal. Posteriormente los ooquistes con dos esporoquistes son expulsados y al madurar se transformarán en cuatro esporozoítos, muy similares a los trofozoítos. Los esporoquistes son eliminados durante una semana o dos, pero no son infecciosos hasta que no estén expuestos a la temperatura, aire y humedad, que permiten su esporulación.
Esto generalmente requiere de 1 a 5 días. Cuando existe una temperatura y humedad adecuadas, los ooquistes pueden conservar su infectividad por más de un año, pero mueren por desecación, agua en ebullición y por el contacto con ciertas sustancias químicas.

El Toxoplasma Gondii es un parásito microscópico (4 a 6 micrones), morfológicamente parecido a la Leishmania, de vida intracelular obligada y que está ampliamente diseminado entre todos los animales de sangre caliente, incluyendo al mono y al hombre. Este puede adquirir el parásito por via oral y digestiva, consumiendo la carne semicruda, particularmente de cerdo, pollo o cordero (pero no se excluye la de res), pues la forma quística es relativamente resistente al débil calor que llega al centro de las piezas, como ocurre en el asado medio. Vale la pena mencionar que los cerdos lo pueden adquirir fácilmente al devorar ratas infectadas, y que entre nosotros esto no tiene nada de raro porque un buen número de cerdos que llegan al mercado de carnes han sido criados en los basureros donde abundan las ratas. El otro animal hoy en día implicado es el gato, tanto porque el parásito tiene predilección por él (quizá también porque consume ratas) y por su íntimo contacto con los humanos que adquieren la infección, bien sea por vía intranasal (goticas de saliva) o por vía oral contaminándose las manos con las deyecciones del animal en la maniobra de cambiarle su letrina. Definitivamente los médicos debemos advertir sobre los peligros de encariñar a los niños con los gatos, así como los obstetras proscribir completamente el contacto de las gestantes con estos animales (aunque no estén aparentemente enfermos, pero pueden ser portadores), sobre todo si se tiene en cuenta que las formas más graves de toxoplasmosis son las consecutivas a infecciones adquiridas durante la gestación. El contagio humano también es factible por fecalismo o por vía intranasal, de donde 
no está por demás tener cuidado con los pacientes sospechosos o confirmados de toxoplasmosis, as í como con los animales de laboratorio requeridos para mantener la cepa viva con destino a la prueba de Sabin y Feldman.

La conclusión práctica de todo esto es muy clara; a toda mujer que queda embarazada, en la primera consulta prenatal, al lado de la serología y de la clasificación sanguínea, se le debe ordenar una inmunofluorescencia indirecta (IFI) para toxoplasma (que detecta primordialmente los anticuerpos ligados a la IgG). Entre el 5 y el $45 \%$ resultarán positivas a título bajo (menos de 1: 1.000), pero esto no quiere decir que tenga toxoplasmosis activa ni se justifica de ninguna manera alarmarlas con presuntos peligros para el niño. Sólo significa que en un pasado probablemente lejano, adquirieron la infección y lucharon exitosamente contra ella. Este hallazgo de título bajo impone, eso sí, la repetición del examen a los cinco meses de gestación, con el fín de detectar la reactivación de la toxoplasmosis y autoriza tratamiento medicamentoso. Ahora bien, cuando el título inicial es de 1: 1.000 o más, conviene ordenar inmunofluorescencia indirecta para IgM; si el resultado es positivo a título menor de $1: 0$, lo más seguro es que la infección no es reciente o por lo menos tiene tres semanas de haber ocurrido; tampoco hay que alarmarse, ni requiere tratamiento, pero, en el control de los cinco meses (o tres semanas) después debe solicitarse de una vez la IFI, IgM y la IgG: Si el IFI IgM permanece igual o se negativiza, se descarga la reactivación, pero si se incrementa en dos o más diluciones es evidencia de la misma. En los trabajos de investigación (o si se es bien académico en el ejercicio de la obstetricia), estos análisis se aplican en el séptimo mes, con los mismos criterios. A las gestantes que han sido negativas en el primer examen, si se tiene conciencia de la prevalencia endémica de esta para- sitosis, conviene repetir el test de $|F|$ alrededor de los siete meses.

La toxoplasmosis es la zoonosis parasitaria más ampliamente difundida en el mundo y se estima que una tercera parte de la población mundial posee anticuerpos contra Toxoplasma Gondii.

La toxoplasmosis puede ser congénita 0 adquirida:

La congénita se presenta con deceso al nacer, o en tres formas clínicas, a saber:

1. La triada de Sabin: hidro o microcefalia, calcificaciones cerebrales en las radiografías y coriorretinitis. Dado que a los recién nacidos poco se les examina el fondo del ojo, lo que induce a verlo es con frecuencia el sólo aspecto de la cabeza, la microoftalmia o el estrabismo muy notorio y fijo que ostentan, unido al hábito que el médico tenga de pensar en toxoplasmosis. Al lado de esto puede observarse ya retardo motor revelado por alteraciones del tono muscular y de los reflejos, propios del recién nacido, así como también convulsiones; esto es lo que delata toxoplasmosis vieja y probablemente cicatrizada, pues se supone que la infección ocurrió al comienzo del período susceptible, es decir entre el tercero $y$ quinto mes, transcurriendo las etapas de infección general $y$ encefalitis dentro del claustro materno.

$\mathrm{Si}$ el título de las IFI lgM es positivo en 1:0 o más, ello denota que aún hay actividad y se justifica el tratamiento de medicación. Con este cuadro clínico y las solas IFI IgM positivas a título significativo (más de 1:1.000), es frecuente que también se administre tratamiento, pero a sabiendas de que se está manejando una secuela o cicatriz, con muy pocas probabilidades de éxito.

2. Cuadro de encefalitis, revelado por convulsiones, perturbaciones del tono 
muscular, parálisis diversas, hipertensión de fontanela (hidrocefalia), así como también el cuerpo vítreo y coriorretivinitis activa. Se supone que han contraido la infección entre el quinto $y$ el séptimo mes $y$ padecieron la etapa generalizada in útero. Su estado de actividad se confirma por la presencia de las IFI IgM a título elevado $y$ se justifica plenamente el tratamiento por medicación, aunque el pronóstico sigue siendo malo inclusive "quod vitan".

3. Cuadro septicémico grave, evidencias de hepatitis, con hepatoesplenomegalia, ictericia y hasta ascitis o anasarca y manifestaciones purpúricas, convulsiones (encefalitis $y$ coriorretinitis activa). Se supone que han adquirido la infección en la etapa final del embarazo, inclusive durante el parto.

A pesar de lo florido del caso, si el niño es examinado antes de cumplir una semana de vida, las IFI IgM pueden estar negativas porque han tenido tiempo de formarse, pero ello no niega el diagnóstico; si se repiten (como es debido) en forma seriada, semanalmente, harán un pico de máxima positividad alrededor del mes. Se justifica el tratamiento con drogas, a sabiendas de que el pronóstico es malo, pues al igual que los del segundo grupo, si no mueren, quedan en la posición de los primeros, es decir, con secuelas irreparables.

La toxoplasmosis adquirida es una enfermedad que prácticamente no da manifestaciones clínicas sino raramente, y la mayoría de la población es portadora sana, aproximadamente el $60 \%$.

\section{Summary}

This paper tries to show the great risk that an apparently normal pregnancy represents to the mother; a death new
Empero para la embarazada el riesgo de que su hijo adquiera la enfermedad, toxoplasmosis congénita, es altísimo: uno por ciento. Como la infección materna es inaparente para la gestante $y$ para su médico y el tratamiento durante el embarazo sí puede ser efectivo, ya que suele prevenir las irreversibles lesiones físicas y el déficit intelectual y visual protuberantes y patéticos en la toxoplasmosis congénita; es meridiano incluir en la primera consulta prenatal, pruebas para toxoplasma, y repetirlas, como se dijo al principio, aún si estas demuestran títulos bajos o inclusive negativos, por cuanto el embarazo reactiva la toxoplasmosis asintomática.

Actualmente se recomienda el tratamiento en el niño así: Spiramicina (Specia) $100 \mathrm{mg} / \mathrm{kg}$. durante un mes: o bien Clindamicina (Upjohn) $15 \mathrm{mg} / \mathrm{kg}$. también durante un mes. La Provamicina (Spiramicina), parece tener menos efectos indeseables que el Dalacín $C$ (Clindamicina) como puede ser la diarrea severa (colitis grave por antibiótico). La dosis para el adulto son las mismas que las usadas para infecciones bacterianas.

\section{Resumen}

El presente escrito sólo quiere destacar el gigantesco riesgo que un embarazo aparentemente normal presenta, ya que este puede concluir en una toxoplasmosis congénita; un recién nacido muerto o vivo, pero deficiente mental, ciego, deforme o incapacitado para el resto de sus días.

born, or alive, but blind, mental defiently, and nhisically handicaped for the rest of this days, due to congenital toxoplasmosis. 


\section{Bibliografía}

1. CORREDOR, A., JULIAO, O. MORENO, G.S., "Documento sobre Toxoplasmosis". En preparación Estudio Nacional de Salud. 1982.

2. CROSSMAN, H., "Manual en Termino. logy and Classification in Mental Retardation". American Association en Mental Deficiency, 161: 161, 1973.

3. HARRISON, "Medicina Interna". La Prensa Mexicana. 1.278: 1.280, 1979.
4. MACKIE, T., HUNTER, G.W., "Manual de Medicina Tropical". La Prensa Mexicana Médica. 316: 318, 1956.

5. Plata-rueda, E., "Estado Actual del Diagnóstico y Tratamiento de la Toxoplasmosis". Pediatría. Vol. XIX No. 1., 19:26, 1982.

6. VILLA, R., y Col. "Niveles de Anticuerpos para Toxoplasma Gondii por Inmunofluerescencia Indirecta". Acta Médica Colombiana. Vol. 6 No. 2. Ab. Jun. 225: 234, 1981. 